\title{
Author Correction: Biodegradable black phosphorus-based nanospheres for in vivo photothermal cancer therapy
}

Jundong Shao, Hanhan Xie, Hao Huang, Zhibin Li, Zhengbo Sun, Yanhua Xu, Quanlan Xiao, Xue-Feng Yu, Yuetao Zhao, Han Zhang, Huaiyu Wang \& Paul K. Chu

Correction to: Nature Communications https://doi.org/10.1038/ncomms12967, published online 30 September 2016.

This Article contains an error in Fig. 4c and Supplementary Figs. 5b and 6d.

In Fig. 4c, the panel representing the MCF7 cells at $20 \mathrm{ppm}$ was inadvertently duplicated. The correct version of Fig. $4 \mathrm{c}$ is

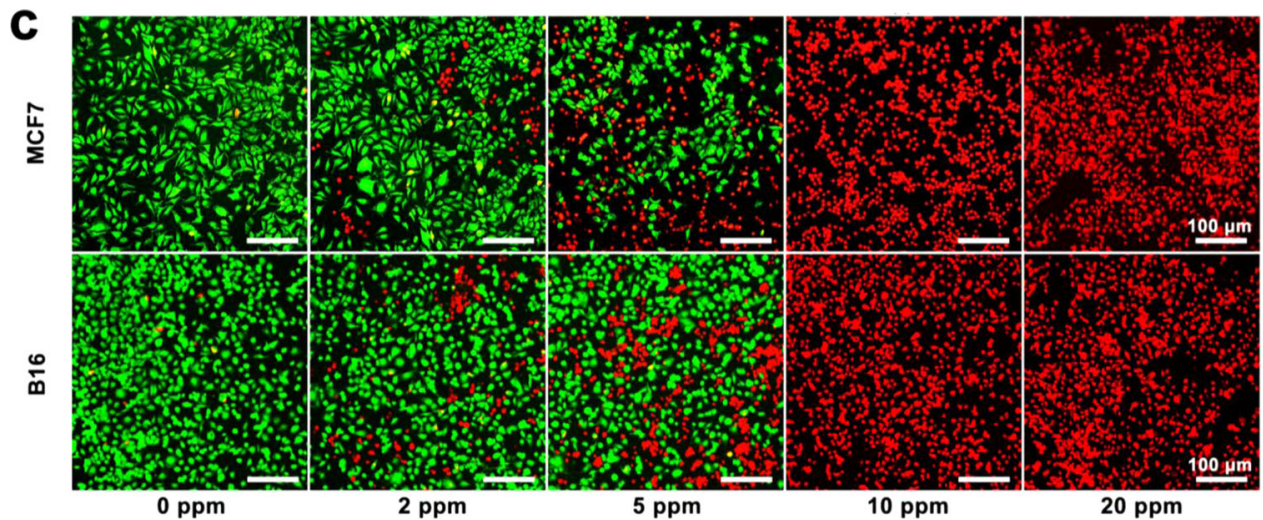


In Supplementary Fig. 5b, the two SEM images for "After irradiation" and "1 week" were not measured on the same batch as the other two SEM images in the figure representing " 4 weeks" and " 8 weeks". The correct version of Supplementary Fig. 5b is

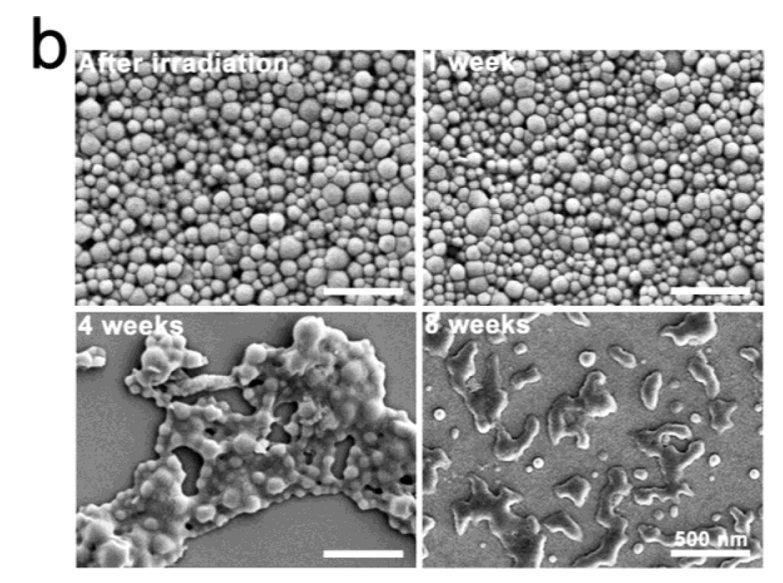

In Supplementary Fig. 6d, the panel representing BPQDs/PLGA NSs at 20 ppm was inadvertently duplicated . The correct version of Supplementary Fig. $6 \mathrm{~d}$ is
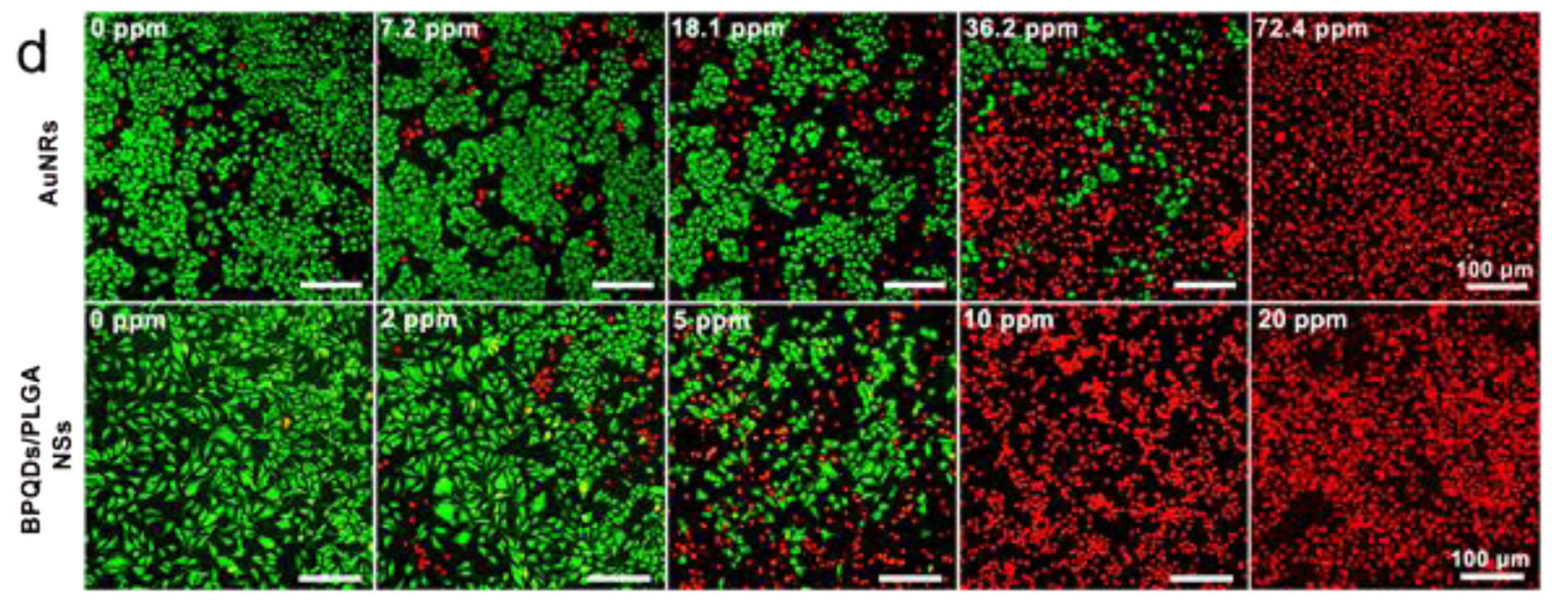

The errors hasve not been corrected in the PDF or HTML versions of the Article.

Published online: 18 June 2021

\begin{abstract}
(c) (i) Open Access This article is licensed under a Creative Commons Attribution 4.0 International License, which permits use, sharing, adaptation, distribution and reproduction in any medium or format, as long as you give appropriate credit to the original author(s) and the source, provide a link to the Creative Commons license, and indicate if changes were made. The images or other third party material in this article are included in the article's Creative Commons license, unless indicated otherwise in a credit line to the material. If material is not included in the article's Creative Commons license and your intended use is not permitted by statutory regulation or exceeds the permitted use, you will need to obtain permission directly from the copyright holder. To view a copy of this license, visit http://creativecommons.org/licenses/by/4.0/.
\end{abstract}

(c) The Author(s) 2021 